\title{
Modern information and mathematical models in construction industry
}

\author{
V. A. Minaev ${ }^{1}$, V. M. Pizengolts ${ }^{2}$, A. O. Faddeev ${ }^{1}$, A.Y. Bystryakov ${ }^{2}$, E.V. Savenkova ${ }^{2, *}$, \\ and $E$. $V$. Kruglikova ${ }^{2}$ \\ ${ }^{1}$ Bauman State Technical University, ul. Baumanskaya 2-ya, 5, 105005, Moscow, Russian Federation, \\ ${ }^{2}$ Friendship University of Russia (RUDN University), 6 Miklukho-Maklaya St., Moscow, 117198, \\ Russian Federation
}

\begin{abstract}
Building information modelling (BIM) - new technology of construction object information maintenance. It allows specifying influence of changes and risks made in it (including geodynamic) at all stages of lifecycle. Objects include products, building equipment, technological platform, the building, engineering, transportation networks and systems of building communication. The model expands possibilities of innovative technologies implementation, allowing creating reasoned economic decisions.
\end{abstract}

\section{Introduction}

The model extends the possibilities of introducing innovative technologies, allowing to formulate sound economic decisions [1]. Confirmation of this can be found in the works [11-14], where are examples of application of models. One of the modern technologies used in the process of building information modelling is BIM-technology [1, 11]. BIM is abbreviation of English word (Building Information Modelling).

The idea of BIM was started in 70th years of previous century and since that develops actively. NBIMS standard (National BIM Standard in the USA) consists that definition of this technology: "Building Information Model (BIM) is physical and functional display of building. The BIM Model is a general informational source, which helps to make responsible decisions and ac-companying the entire life cycle of the structure from conception to demolition".

BIM-technologies operate with visual (infografical) introduction, which are given by evidences, images, bodies and real space bodies and etc. $[1,13]$. Such a representation allows for a precise description of the form of the object to impose various interpretations of its functional content. Wherein:

1. BIM models and control objects are not just a graphical objects, it is information, allowing you to automatically create drawings and reports, perform project analysis,

* Corresponding author: savenkova.rudn@mail.ru 
simulate the schedule of work performance and operation of facilities etc., provide builders with a reliable basis for making optimal decisions taking into account all available data.

2. BIM allows specialists to use this information throughout their life cycle efficiently and collectively, eliminating redundancy, re-entry and loss of data, errors in their use, and the use of modern tools for analyzing, planning and managing construction and upgrading of objects transfer and transformation.

Note that three-dimensional (3D) models are used for visualization of objects for a long time, but the information base of support and professional openness realized in BIM-models accessible to a wide range of interested specialists has arisen only in recent years.

BIM is a complex tool that uses a three-dimensional database, one for the model and design tools, replenished and improved in the named process. The basis of BIM technology is the creation of a single integrated information environment of common data CDE (Common Data Environment).

The data for implementing the BIM technology is selected by specifying an almost point-by-point representation of the object, obtained, for example, by making measurements and specifying a parametric building model that combines the 3D model and external data. And each element of the model can be assigned additional attributes. The peculiarity of this approach is that the building object is actually designed as a systemic whole. Changing any of its parameters entails the automatic change of other related parameters, objects and documentary support.

Basic stages of information modelling

Using the BIM technology involves working directly with the buildings model from any kind (plans, sections, specifications) with the ability to make automatically synchronized changes. The model due to the presence of the interdependence of all elements is correctly updated and allows to generate updated project documentation automatically.

The main tasks solved by the introduction of BIM-technology are:

- Improving the quality of the project documentation and shortening the design time;

- work with a single database about the object and obtain objective information about it;

- operating with a visual model;

- Increasing the coordination of the participants in the design and construction process;

- Increase the efficiency of the used software.

Information modelling of the building is a new approach to the erection, equipping, maintenance, repair and modernization of the building (that is, to manage its life cycle). That presupposes the complex collection and processing in the design process of all architectural and engineering, technological, economic and other information about the building with all its interrelations and dependencies, when the building and everything that relates to it are considered as a single object.

The complex association of the various interacting objects (the building and its equipment) life cycles in a single system is shown in Figure 1 [11]. The buildings life cycle, information provided by BIM-technologies, is presented in Figure 2 in association with the life cycle of the territory [11].

By creating an accurate digital information model of an object, the integrated general information environment (CDE) allows all participants in the investment and construction process to receive and exchange the necessary information about the construction / design / upgrade object at any time in accordance with the regulations.

Due to CDE, BIM technology allows the investor to control the use and expenditure of funds at all stages of the buildings project implementation, and integration with the life cycle of the territory allows to take into account changes in the characteristics of the territory of the change in the buildings parameters and vice versa.

Geodynamic risks modelling 
The buildings location, depending on its geographic location, climate and other factors, re-quires additional facility research to ensure its safe construction and operation. It is known that in recent years the number of dangerous major man-made disasters and dangerous natural phenomena has been growing steadily. The risks of emergencies arising from human activities and global terrestrial changes pose a significant threat to buildings and structures $[2-4]$.

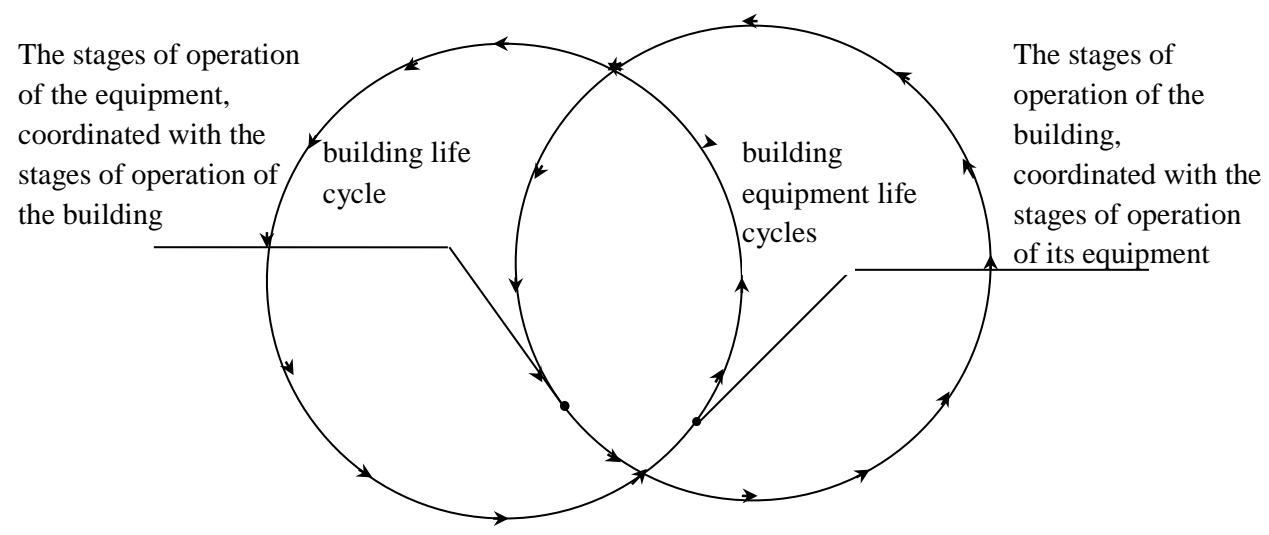

Fig. 1. Building life cycles complex integration and its equipment.

To determine the changes in buildings and the location, each of the objects monitoring is used. The number of monitored parameters during the monitoring includes dozens of parameters, for ex-ample, linear dimensions, angular dimensions, deviations from the co-location of landmarks, coincidence of axes, symmetry of the installation, coincidence of surfaces, etc. The fixing of such data determines the changes in the most vulnerable elements functioning: building structures, engineering networks, etc.

Security threats are also associated with the building life cycles, its structures and territories, the wear and tear of engineering, transport networks and building communication systems.

Locations of buildings possible destruction and structures on a specific territory can be deter-mined with sufficient accuracy on the basis of calculations using geodynamic risks models. The basic idea underlying such models is related to the description, analysis and evaluation of seismic-deformation processes in the territorial-dynamic aspect [5-10]. There is an example of the equipotential distribution of probabilistic geodynamic risk calculated [15] for the real territory of the planned building on Figure 3.

The main means of combating such threats is also to monitor each of these objects. And the result of monitoring can be a decision to strengthen the location of the building, the foundation of the building, strengthen the construction of the building through the use of modern technology, modernization of construction sites [14]. In particular, the technology of an "intelligent building" can be applied, on the basis of which a structured system for monitoring and controlling engineering equipment is organized. 


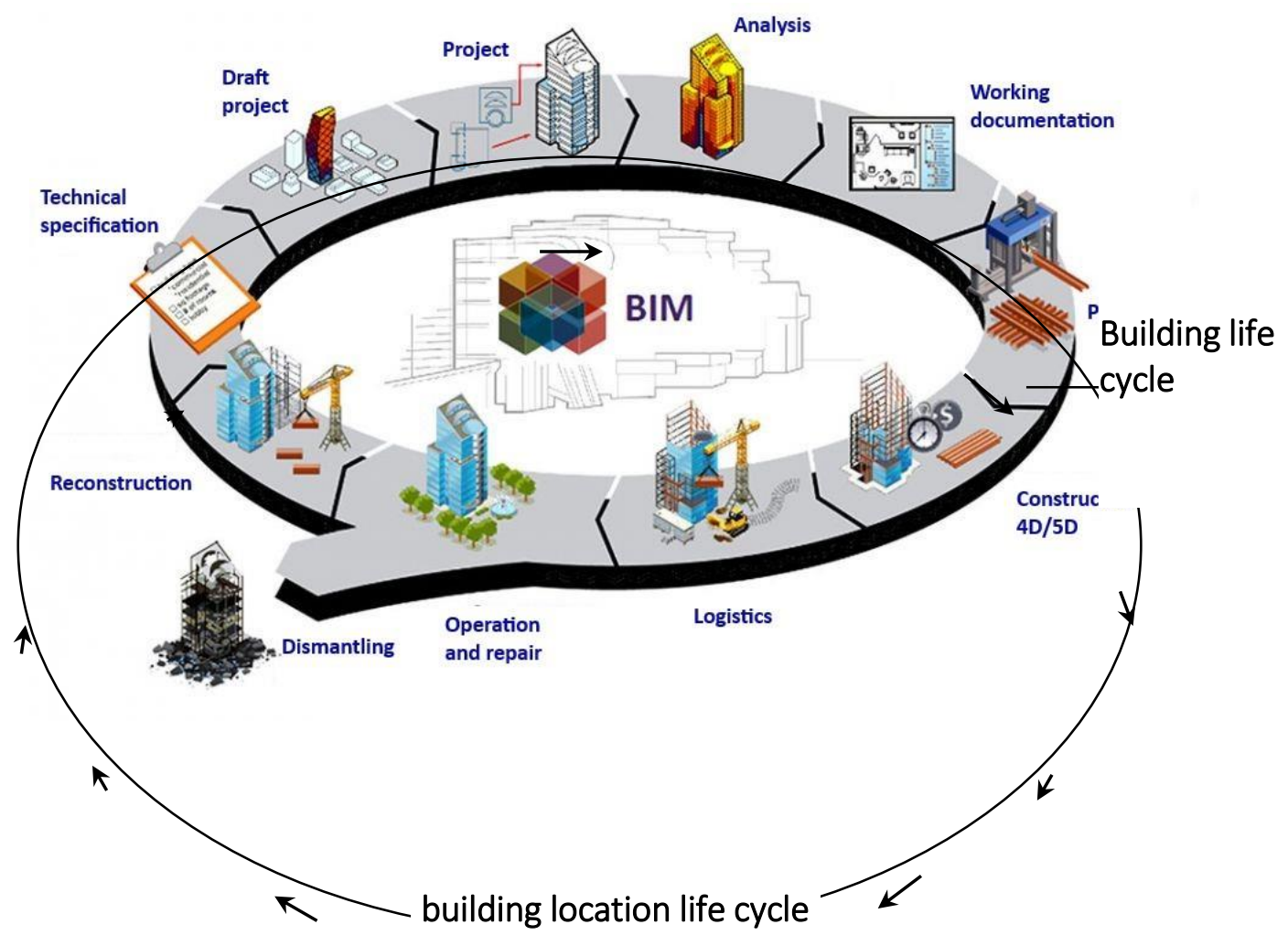

Fig. 2. Complex integration of building life cycles and its location.

This system should monitor the following major destabilizing factors:

- violations in the heating system, cold and hot water supply caused by the failure of engineering equipment at central heating points, in boiler rooms, as well as by accidents on pipelines and malfunctions in heating appliances;

- violations in the supply of electricity;

- refusals in the elevator equipment operation;

- fire-dangerous situations occurrence;

- Increase in the level of radiation and poisonous substances;

- flooding of premises, drainage systems and technological pits;

- gas leak;

- deviation from the regulatory production processes parameters that can lead to emergencies. 


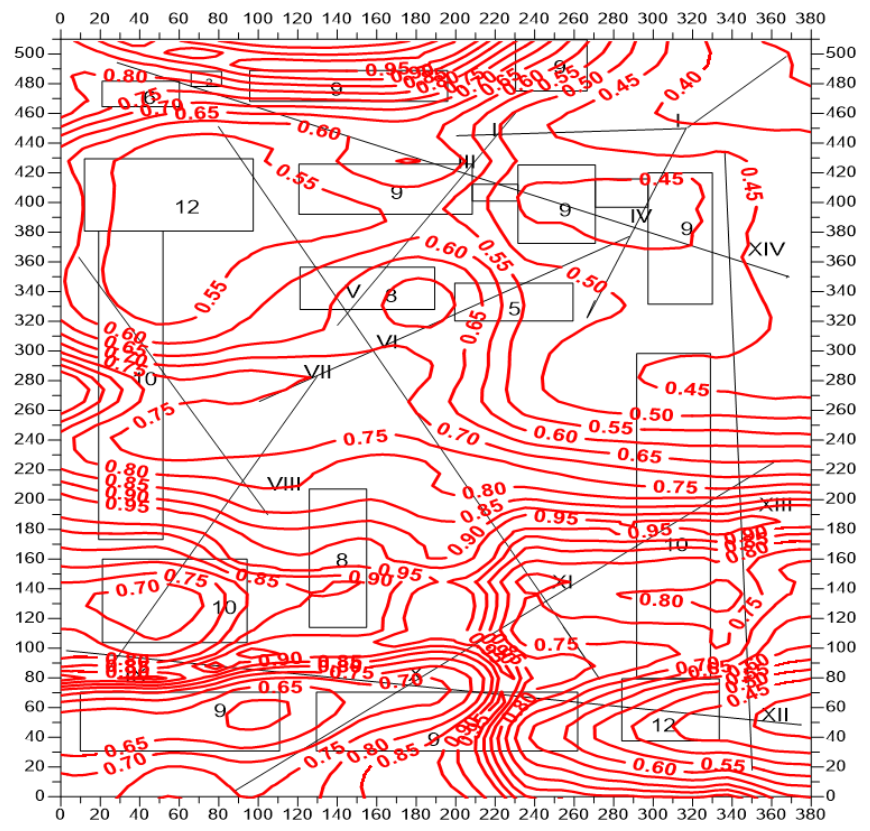

Fig. 3. Probabilistic geodynamic risks equipotential distribution for the planned development territory (the digits denote the probabilities/ Risk ranging from 0 to 1; Rectangles - planned buildings).

This system should monitor the following major destabilizing factors:

- violations in the heating system, cold and hot water supply caused by the failure of engineering equipment at central heating points, in boiler rooms, as well as by accidents on pipelines and malfunctions in heating appliances;

- violations in the supply of electricity;

- refusals in the elevator equipment operation;

- fire-dangerous situations occurrence;

- Increase in the level of radiation and poisonous substances;

- flooding of premises, drainage systems and technological pits;

- gas leak;

- deviation from the regulatory production processes parameters that can lead to emergencies. These factors identification determines the decision-making on the prompt disconnection of the engineering communications systems faulty section and the implementation of work to eliminate the malfunction and restore the lost function of the building, related to such types of reconstruction as repair, reconstruction, restoration [14]. Organizational and technological solutions aimed at preserving and restoring the functions of buildings and structures at the stage of reconstruction should provide for the application of means of protecting the functional life of the building, monitoring the parameters of the technological process ensuring emergency shutdown of equipment, stopping the technological process and Timely receipt of information on the occurrence of dangerous situation.

\section{Geoinformation systems}

It should be noted that BIM technology facilitates the creation of a Geo Information System (GIS), which is able to operate with the most detailed information about these layers and 
support investment decision making. GIS development enables investors to have an accurate idea of the building's readiness at various stages of its life cycle to investments in material and financial resources. At the same time, each investor can individually invest only at his own stage, but in the end the whole model, filled with information on the stages and layers, will make it possible to have an accurate picture of the status of the construction project, modernization to investment. Forming spatial information about each stage BIMtechnology allows, along with traditional geodetic survey methods, to apply highperformance ground, air and space scanning measuring systems, as well as modeling methods, which today are one of the most effective and relatively inexpensive collecting and recording spatial Data methods. The scanning and modeling result is complex information about the construction and modernization object (drawings, drawings, photographs, video, available databases, model calculations results, etc.), which represents the initial data for creating information models of stages and layers, as well as geodynamic models of construction risks and modernization. To date, a sufficiently developed methodological and program-algorithmic support for the implementation of both BIM-technologies [1, 11-14], as well as geodynamic risks analysis and prediction in the construction sector has been created $[8,10-12,15]$. However, effective integration of these important areas has not been implemented so far, without which the support of the process of construction and modernization of various facilities cannot meet the current economic and technological requirements of builders and investors, nor the world-wide safety standards for construction sites. At the same time, it is obvious that today it is impossible to implement BIM-technologies fully and build adequate models of geodynamic risks (at the local, regional and regional levels) without additional investment in the development of specialized software and algorithmic support. Although a sufficiently adequate basis for the practical implementation of these technologies is theoretically justified and practically tested, which makes it possible in the short term to solve rather complicated tasks of modernization and construction of objects of any complexity and scale. In Russia over the past five years, the technology of information modeling in the field of construction and design of civil and industrial facilities, as well as analysis and prediction of geodynamic risks has become widespread. More and more companies, both public and private, are investing in upgrading their assets to implement BIM technology at all stages of the facility life cycle. BIM technology was also supported at the state level: a plan was adopted for the phased introduction of BIM technologies in the field of industrial and civil construction, approved by the Ministry of Construction of Russia [16].

\section{Conclusions}

1. Building information model gives the opportunity to substantiate economic and technological solutions and to accompany the entire life cycle of the structure from conception to demolition on a new qualitative level.

2. Building informational Modelling is a new approach, involving the complex collection and processing in the design process of all architectural, engineering, technological, economic and other information about the building with all its interrelations and dependencies. In this case, the building and everything that has to do with it, are considered as a single system object.

3. BIM-technologies capabilities system integration and models of geodynamic risks makes it possible to design, build and operate modern buildings and facilities at a principally new level, and monitor their safety using GIS technologies.

4. BIM-technology allows to operate with the most detailed information when making investment decisions, enables investors to have an accurate readiness of the building 
representation at its various implementation stages to invest in material and financial resources.

This publication has been prepared with the support of the "RUDN University Program 5-100".

\section{References}

1. Y. D. Kosorukov, A. Fateev, V. I. Svetlakov, S. A. Tabakov, Resources and Waste, 2 (2015)

2. V. A. Minaev, A. O. Faddeev, A. V. Kantysheva, T. M. Nevdah, T. R. Akhmetshin, Modelling, Optimization and Information Technology 6, 4 (2018)

3. V. A. Minaev, A. O. Faddeev, N. A. Kuz'menko, RTSoft - Cosmoscope, 256 (2017)

4. V. A. Minaev, A. O. Faddeev, R. M. Danilov, Special Equipment and Communication 1, 48-52 (2011)

5. V. A. Minaev, A. O. Faddeev, A. V. Abramova, S. A. Pavlova, Technologies of Technospheric Security 5, 51 (2013)

6. V. A. Minaev, A. O. Faddeev, A. V. Abramova, S. A. Pavlova, Special Equipment and Communication 5, 58-63 (2013)

7. V. A. Minaev, A. O. Faddeev, N. G. Topolsky, Modeling of geodynamic risks in emergency situations (Khabarovsk, Publishing house of the FENU of the Ministry of Internal Af-fairs of Russia, 2014)

8. V. A. Minaev, A. O. Faddeev, N. G. Topolsky, Technologies of the Technospheric Safety 1, 53 (2014)

9. V. A. Minaev, A. O. Faddeev, A. V. Abramova, Problems of Risk Management in the Technosphere 1, 29, 90-99 (2014)

10. V. A. Minaev, A. O. Faddeev, K. M. Bondar, N. A. Kuzmenko, T. M. Nevdakh, Journal of Special Equipment and Communication 6, 37-45 (2015)

11. V. A. Minaev, A. I. Mokhov, A. O. Faddeev, Management of the Development of the Territory 1, 54-58 (2016)

12. V. A. Minaev, A. I. Mokhov, V. M. Pizengolts, International Scientific Journal 5, 40-47 (2016)

13. A. I. Mokhov, Reorganization, Organizational and Anthropotechnical Reliability of Construction, 129-163 (2005)

14. A. I. Mokhov, Models of modernization of industrial enterprises (in: Innovation processes in the Russian economy. Ed. Veselovsky, Kirova, Publishing House "Scientific consultant", 2016)

15. V. A. Minaev, N. G. Topolsky, A. O. Faddeev, K. M. Bondar, A. V. Mokshantsev, Geo-dynamic risks and construction: mathematical models (Moscow, Academy of State Fire Service of the Ministry of Emergency Measures of Russia, 2017)

16. On approval of the Plan for the phased introduction of information modeling technologies in the field of industrial and civil construction. Electronic resource: http://www.minstroyrf.ru/upload/iblock/383/prikaz-926pr.pdf. Access mode on $03 / 11 / 2017$. Authors should use the forms shown in Table 3 in the final reference list. 